\title{
A sanção cognitiva e a sanção pragmática nos romances policiais da década de 1970
}

Fernanda MASSI

(Universidade Estadual Paulista,

Araraquara/FAPESP)

Arnaldo CORTINA

(Universidade Estadual Paulista,

Araraquara/CNPq)

RESUMO: Partindo da semiótica greimasiana, este trabalho analisa o esquema narrativo de quatro romances policiais da década de 1970 e apresenta as diferenças entre as duas sanções encontradas: sanção cognitiva e sanção pragmática. Dois romances seguem o modelo clássico de romance policial, enquanto os outros dois apresentam exceções.

PALAVRAS-CHAVE: sanção; detetive; criminoso

RÉSUMÉ: À partir de la sémiotique greimassiene, ce travail analyse le schéma narratif de quatre romans policiers datant des anées 1970 ; y sont présentées les differénces entre les deux types de sanctions qui s'en dégagent: la sanction cognitive et la sanction pragmatique. Deux de ces oeuvres suivent le modèle classique du roman policier, tandis que les deux autres présentent plutôt des exceptions.

MOTS-CLÉS: sanction; détective; assassin 


\section{INTRODUÇÃO}

O romance policial tem como característica mais marcante o suspense e é, por essa razão, um dos gêneros literários mais lidos em todo o mundo. Criado no século XIX com Edgar Allan Poe, esse tipo de romance possui três elementos fundamentais que compõem sua estrutura: o criminoso, o detetive e a vítima. É o criminoso que, ao assassinar ${ }^{1}$ sua vítima, aciona o fazer do detetive. Todas as obras do gênero policial seguem a mesma receita a fim de não descaracterizá-lo e, assim, contribuem para seu fortalecimento enquanto gênero.

A partir do conceito de esquema narrativo proposto pela semiótica da Escola de Paris é possível observar como ele se apresenta nos romances policiais. O que se pode observar é que esse esquema é composto pelo percurso narrativo do criminoso e pelo percurso narrativo do detetive. Esses percursos são constituídos em quatro etapas distintas, que correspondem à manipulação, à competência, à performance e à sanção. Embora ocorram separadamente, os dois percursos se cruzam na performance do detetive (a investigação), que consiste numa sanção, ou reconhecimento, sobre o fazer do criminoso (o crime).

Na primeira etapa, um sujeito denominado destinador-manipulador manipula outro sujeito para que ele se torne o criminoso ou o detetive. Em geral, o sujeito detetive é escolhido porque já realizou profissionalmente investigações antes de ser manipulado, ao passo que o criminoso pode nunca ter cometido outro crime antes. A manipulação sobre o detetive e sobre o criminoso pode ocorrer de quatro maneiras distintas, quais sejam, a tentação, a sedução, a intimidação ou a provocação. Há ainda a possibilidade de não haver um destinador-manipulador de um desses sujeitos, de modo que é ele próprio, o criminoso ou o detetive, quem realiza a manipulação, denominada, portanto, de auto-manipulação. Na segunda etapa, o sujeito criminoso e o sujeito detetive, cada qual em seu programa, adquirem a competência necessária para a realização de seu fazer, respectivamente, o crime e a investigação. No percurso do criminoso, essa competência consiste nas condições para que o crime seja realizado, sendo elas correspondentes ao local do crime, ao instrumento utilizado para o assassinato, à maneira como ele irá abordar a vítima etc.; no percurso do detetive, a competência consiste no modo como fará a investigação, isto é, quais sujeitos serão interrogados, quais locais serão visitados e revistados, quais instrumentos (supostas armas do crime) serão avaliados etc.

Enfim, a performance é a etapa do esquema narrativo mais importante, tanto no percurso do criminoso quanto no percurso do detetive. No percurso do criminoso a performance é o crime realizado e motivado por alguma paixão, seja ela simples ou complexa, que pode ser representada pela vingança, pelo ciúme, pela ganância etc. Esse crime aciona o fazer do detetive para que ele realize sua performance. A performance do detetive, qual seja a investigação, é uma sanção no percurso do criminoso. Em outras palavras, pode-se dizer que a performance do detetive é o ponto onde se encontram os percursos dele e do criminoso, já que ele será sancionado positiva ou negativamente por aquele. Após realizar a sanção sobre o criminoso, o detetive entrega-o a um destinadorjulgador para que seja punido ou perdoado. O destinador-julgador é figurativizado, geralmente, pela polícia, por ser ela a representante da instituição encarregada de restabelecer a ordem social. Nem sempre a punição recebida pelo sujeito criminoso, 
porém, é descrita, pois ela é apenas uma conseqüência do fazer realizado pelo detetive, que é o aspecto mais importante da narrativa policial. Sendo assim, muitos romances policiais terminam quando o criminoso é encontrado, de modo que o leitor geralmente não fica sabendo se o assassino foi preso, enforcado ou assassinado, pelo crime que cometeu.

\section{A SANÇÃo COGNITIVA E A SANÇÃo PRAGMÁTICA}

A sanção realizada pelo detetive sobre o fazer do criminoso pode ser classificada de duas maneiras, segundo Martins (2000): sanção cognitiva e sanção pragmática ${ }^{2}$. A sanção cognitiva aparece nas chamadas "narrativas de detetive”, e, nelas, o fazer do detetive consiste em descobrir a identidade do criminoso. Já na sanção pragmática, que aparece nas "narrativas de criminoso", o detetive conhece a identidade do criminoso desde o início e sua performance consiste em persegui-lo para provar que ele é o culpado. Isso porque, embora o detetive tenha sido escolhido para realizar a investigação, não basta que ele aponte o criminoso sem que tenha provas para a acusação.

Neste trabalho, analisamos três romances e um conto policiais que, na década de 1970, apareceram na lista das obras mais vendidas no Brasil, a partir de um levantamento realizado por Cortina (2004). Trata-se de Assassinato no Expresso Oriente, "Os três ratos cegos" (conto) e Um corpo na biblioteca, de Agatha Christie, e O dia do Chacal, de Frederick Forsyth. Dois desses romances são narrativas de detetive, que apresentam a sanção cognitiva, e os outros dois são narrativas de criminoso, que apresentam a sanção pragmática.

Para que se consiga compreender melhor a distinção entre sanção cognitiva e a sanção pragmática, descreveremos sucintamente o enredo de cada um deles, separados de acordo com o tipo de sanção que apresentam. Em seguida, mostraremos as diferenças entre a sanção cognitiva e a sanção pragmática e a influência de cada uma delas na caracterização do gênero policial.

\subsection{SANÇÃO COGNITIVA}

No romance Assassinato no Expresso Oriente, o crime ocorre dentro de um vagão de trem e é realizado por doze assassinos. A vítima é Mr. Ratchett, um homem que seqüestrou a criança Daisy Armstrong e que, após ter recebido o dinheiro do resgate, entregou o cadáver dela à família. Em conseqüência desse fato, a mãe de Daisy teve um aborto espontâneo e morreu na mesma hora, o pai morreu de desgosto e a empregada suicidou-se para não ser acusada de envolvimento com os crimes. A partir das quatro mortes (a da jovem Daisy, de sua mãe, de seu pai e da empregada), os familiares e alguns empregados dos Armstrong resolveram se vingar de Mr. Ratchett. A vingança, portanto, é a paixão motivadora desse assassinato, ou seja, foi ela que manipulou os doze sujeitos a se tornarem criminosos. Como parte da competência para o crime, os assassinos descobriram o dia em que Mr. Ratchett tomaria o Expresso Oriente e compraram doze passagens, para que sobrassem poucos lugares no trem além deles e da vítima. O que os surpreendeu, contudo, foi que o diretor da empresa de trens, Bouc, resolveu tomar o Expresso Oriente naquele mesmo dia e ainda levou consigo o amigo e 
detetive Hercule Poirot. Mesmo assim, os criminosos decidiram prosseguir com o plano e assassinaram Mr. Ratchett em sua cabina, no momento em que o trem foi retido pela neve. Um deles envenenou o copo de água da vítima antes de ele dormir para que, em seguida, todos os outros o apunhalassem. Logo no dia seguinte, Hercule Poirot foi acionado pelo destinador-manipulador Bouc para realizar a investigação. Bouc queria que Poirot encontrasse o assassino antes de o trem chegar a seu destino. Com isso, o detetive foi obrigado a agir rapidamente e começou sua performance interrogando todos os passageiros. Além das entrevistas, Poirot revistou o quarto da vítima e foi lá que encontrou um pedaço de papel com a palavra “...strong”. O detetive conhecia o caso Daisy Armstrong e logo deduziu que a vítima era, na verdade, o assassino da menina sequiestrada. Poirot se aprofundou na investigação sobre a vida de cada um dos passageiros e descobriu que todos eles tinham alguma ligação com a família Armstrong, e que tinham cometido o crime conjuntamente com a intenção de se vingar de Mr. Ratchett. Com essa descoberta, o detetive Hercule Poirot realizou uma sanção cognitiva sobre o fazer dos criminosos, que tiveram sua identidade secreta revelada por ele. Após encontrar os assassinos, Poirot os entregou ao destinador-julgador Bouc para que decidisse qual seria a punição recebida por eles. Bouc, que também conhecia o caso Daisy Armstrong, decidiu não entregar os criminosos à polícia, já que eles tinham se vingado de um assassino, que estava sendo procurado há muitos anos. O diretor da empresa de trens tornou-se, portanto, cúmplice do crime e preferiu contar à polícia uma versão da história na qual o assassino teria fugido pela janela enquanto o trem estivera retido pela neve. Enfim, a sanção realizada pelo detetive sobre o fazer do criminoso é do tipo cognitivo.

Outro romance policial que também apresenta esse tipo de sanção é Um corpo na biblioteca, de mesma autoria. Nessa narrativa, dois sujeitos são manipulados a se tornarem criminosos por tentação, isto é, eles cometem o crime visando receber uma herança em troca. Mark Gaskell era genro de um velho muito rico, Jefferson, que pretendia deixar sua herança para ele e para a nora; o velho, porém, conheceu uma garota chamada Ruby Keene e pretendia adotá-la, para que ela ficasse com toda a sua fortuna. Ruby era prima de Josephine e as duas trabalhavam no Hotel Majestic, onde conheceram Mark e Jefferson. Josephine e Mark tinham um caso amoroso e para que ele não perdesse a herança para Ruby, os dois decidiram assassiná-la. Para isso, envenenaram a garota e incendiaram seu corpo na pedreira da cidade dentro de um carro roubado. Sabendo que a morte de Ruby não seria aceita sem um corpo para comprovála, Mark e Josephine assassinaram outra jovem, que não tinha nenhuma relação com a história, e abandonaram o corpo dela na biblioteca de um jovem de má reputação, Basil Blake, conhecido no bairro pelas festas que promovia para jovens, nas quais oferecia bebidas e drogas aos convidados. Basil, por sua vez, decidiu se livrar do corpo assim que o encontrou e o levou para a biblioteca da casa do Sr. Bantry. No dia seguinte, a esposa do Sr. Bantry encontrou o corpo em sua casa e chamou imediatamente a polícia e sua amiga Miss Marple. Ela enalteceu as habilidades detetivescas de Miss Marple e pediu-lhe que fizesse a investigação; com isso, a velha foi manipulada a tornar-se o sujeito detetive por sedução. Miss Marple não era um detetive profissional, mas possuía a competência necessária para a investigação, porque estava acostumada a desvendar os mistérios da aldeia em que morava, St. Mary Mead. Para realizar sua performance, a velha se hospedou no Hotel Majestic e coletou o máximo de informações possíveis 
sobre os envolvidos. Em seguida, conversou com Basil Blake, a quem ela julgava inocente, e com o velho Jefferson, que conhecia muito bem a vítima. Logo, Miss Marple descobriu que Mark Gaskell era um dos herdeiros de Jefferson e que ele tinha um caso com Josephine Turner, prima de Ruby. Josephine tinha acionado a polícia em virtude do desaparecimento da garota e tinha sido a única pessoa a reconhecer o corpo da vítima encontrada na casa dos Bantry. Dessa forma, Miss Marple realizou uma sanção cognitiva sobre o fazer do criminoso.

\subsection{SANÇÃO PRAGMÁTICA}

O conto policial “Os três ratos cegos”, de Agatha Christie, apresenta a sanção pragmática do detetive, Tanner, sobre o fazer do criminoso, Jim. Isso quer dizer que o detetive conhecia a identidade do criminoso desde o início da narrativa e seu fazer consistia em persegui-lo. Mesmo sendo um romance de sanção pragmática, com as características descritas acima a respeito da identidade do criminoso, foi o fazer do criminoso que acionou o fazer do detetive, ou seja, é o crime que impulsiona a investigação. Jim, o criminoso, planejou assassinar três vítimas para se vingar dos maus tratos recebidos na infância. Quando era criança, ele e seus dois irmãos foram exilados da guerra e entregues aos cuidados de um casal, os Gregg. O Sr. e a Sra. Gregg, por sua vez, negligenciaram os cuidados que deveriam dispensar às crianças e uma delas faleceu. $\mathrm{O}$ casal foi preso imediatamente, mas o marido morreu tentando fugir de carro e a esposa teve que cumprir a pena sozinha. O segundo irmão de Jim, por sua vez, enlouqueceu e ele, em nome dos três irmãos, resolveu se vingar das pessoas que tinham contribuído para o sofrimento deles. A primeira a ser escolhida foi a Sra. Gregg, que tinha acabado de sair da prisão. Para adquirir a competência necessária para a realização do crime, Jim descobriu onde a Sra. Gregg morava e foi visitá-la. Ele enforcou sua primeira vítima com as mãos, mas, ao sair do prédio em que a velha morava, deixou cair um caderninho com os nomes das próximas vítimas e o local onde iria encontrá-las. Com isso, a polícia descobriu que um criminoso, até então não identificado, estava planejando assassinar mais duas pessoas e que ele continuaria a realizar sua performance criminosa na pensão Monskell Manor, recém-instalada na cidade. Sob mandado policial, o inspetor Tanner foi enviado à pensão à paisana. Assim que chegou, descobriu que Jim era o criminoso, pois ele tinha se apresentado como policial aos outros hóspedes e tinha dito que estava à procura de um suposto assassino (ele mesmo). Tanner não prendeu Jim imediatamente, porque não tinha como provar que ele era o culpado pela morte da Sra. Gregg. Com isso, Jim teve tempo de realizar sua segunda performance e assassinou a Sra. Boyle, que tinha sido a responsável pela distribuição das crianças exiladas da guerra entre os casais da comunidade. Tanner descobriu que Molly, a próxima vítima, tinha sido a diretora da escola em que Jim e seus irmãos tinham estudado e que ela tinha negado ajuda a eles quando lhe enviaram uma carta. Depois disso, o criminoso continuou sustentando a mentira de que era um inspetor de polícia e pediu aos hóspedes que recompusessem a cena do crime. O detetive aproveitou a situação para flagrar o criminoso em sua terceira performance e ficou escondido numa sala junto com Molly. Quando Jim tentou assassiná-la, Tanner surpreendeu-o e decretou sua prisão. Assim, o detetive realizou uma sanção pragmática sobre o fazer do criminoso e o prendeu para puni-lo de seu crime. 
No último romance policial a ser discutido neste trabalho, a sanção também é do tipo pragmático. Trata-se de $O$ dia do Chacal, de Frederick Forsyth, o único que não é de autoria de Agatha Christie. Nele o detetive também já conhecia a identidade do criminoso desde o início da narrativa e seu fazer consistiu em persegui-lo para que fosse punido. O fazer do detetive, porém, foi realizado com tanto êxito que o criminoso não conseguiu realizar sua performance. Isso ocorreu porque a performance a ser realizada pelo sujeito criminoso, Chacal, consistia em assassinar o presidente francês, General Charles De Gaulle; crime que já tinha sido evitado outras duas vezes. Com a descoberta de que mais uma tentativa de assassinato ao presidente ocorreria no "Dia da Libertação Francesa”, o detetive Claude Lebel, o melhor do país, foi acionado pela polícia francesa para iniciar a investigação. Como ele foi contratado e receberia uma recompensa em dinheiro, a manipulação ocorreu por tentação. Lebel passou a narrativa toda perseguindo o assassino e só conseguiu capturá-lo minutos antes de ele atirar em De Gaulle, durante o desfile do "Dia da Libertação Francesa”. Chacal conseguiu disparar o primeiro tiro, mas o presidente escapou dele quando abraçou um dos homenageados. Lebel entrou na sala onde Chacal se escondia junto com seu acompanhante, o policial Valremy, e acertou um tiro nele. Antes que pudesse reagir, Chacal foi agarrado por Lebel e algemado. Assim, a narrativa se encerrou com a realização de uma sanção pragmática do detetive sobre o fazer do criminoso.

\section{A COERÊNCIA DA SANÇÃO COGNITIVA E DA SANÇÃO PRAGMÁTICA COM O GÊNERO “ROMANCE POLICIAL”}

A partir da leitura e da análise dessas quatro narrativas policiais e das obras que nos deram sustentação teórico-metodológica, que estão apresentadas nas referências bibliográficas, depreendemos algumas características dos romances policiais.

Como foi dito no início deste artigo, o romance policial é composto por dois percursos narrativos - o do detetive e o do criminoso - e algumas de suas características serão agora apresentadas, enfocando as diferenças entre os romances que apresentam a sanção cognitiva e os romances que apresentam a sanção pragmática.

A primeira delas é que o fazer do criminoso desencadeia o fazer do detetive, ou seja, é a partir do crime que o detetive é manipulado para fazer a investigação. Nos quatro romances policiais analisados neste trabalho, só o romance $O$ dia do Chacal não respeitou essa regra. Pode-se dizer, porém, que nesse romance o detetive foi manipulado a fazer a investigação porque o crime a ser realizado já estava planejado e já tinha, inclusive, dia e hora marcados. Além disso, o assassinato do presidente Charles De Gaulle só foi evitado porque o detetive Claude Lebel agiu de maneira eficiente. Portanto, essa característica pode ser atribuída tanto aos romances de sanção cognitiva quanto aos romances de sanção pragmática, e o crime que desencadeia o fazer do detetive pode ser realizado na narrativa, como ocorreu nas obras Um corpo na biblioteca, "Os três ratos cegos” e Assassinato no Expresso Oriente, ou num momento anterior a ela, quando a história tem início e o criminoso já realizou sua performance. No caso do romance Assassinato no Expresso Oriente, não podemos dizer que o crime já tinha sido realizado quando a história teve início, pois não foi esse o assassinato que motivou a investigação de Hercule Poirot; ao contrário, o seqüestro e a morte da menina Daisy Armstrong foram a motivação dos criminosos para o assassino de Mr. Ratchett. 
Nos romances policiais de sanção cognitiva, narrativas de detetive, a identidade do criminoso não é compartilhada com nenhum outro sujeito, a não ser que o crime seja cometido por mais de uma pessoa. Nas duas narrativas de detetive descritas neste trabalho, o saber sobre a identidade do criminoso só era conhecido pelos sujeitos envolvidos com o crime. No romance Assassinato no Expresso Oriente, os doze assassinos conheciam a identidade um dos outros porque se uniram para assassinar $\mathrm{Mr}$. Ratchett e entraram num pacto de silêncio para que nenhum deles fosse descoberto por Hercule Poirot. Assim, quando o detetive Poirot iniciou a investigação, percebeu que os doze passageiros do Expresso Oriente promoviam álibis entre eles, mesmo que alegassem não se conhecer. O romance Um corpo na biblioteca, por sua vez, foi cometido por dois assassinos, que pretendiam conseguir dinheiro com a performance criminosa, e nenhum outro sujeito da narrativa conhecia a identidade deles. Isso mostra que um sujeito só compartilha sua identidade criminosa com outro quando ainda não realizou o crime e está à procura de um comparsa para isso. Tanto é que, embora isso não tenha acontecido em nenhum dos dois romances de sanção cognitiva, o criminoso continua executando sua performance sobre todos aqueles que podem contribuir para a revelação da sua identidade, ou seja, após ter realizado o primeiro crime, o criminoso continua matando as outras pessoas que o descobrem antes que elas dêem qualquer informação ao detetive.

Na sanção pragmática, ao contrário, a identidade do criminoso já é conhecida pelo detetive desde o início da narrativa. Neste trabalho, mostramos que nas narrativas de criminoso o narrador opta por contar ou não ao leitor, no início, quem é o criminoso, mesmo que ele já seja conhecido pelo detetive. No romance $O$ dia do Chacal o leitor sabe desde o início da narrativa que um sujeito denominado Chacal pretendia assassinar o General De Gaulle, ou seja, Chacal tinha sido manipulado para realizar a performance criminosa. Isso ocorre também, porque esse romance é narrado sob a perspectiva, entre outras, do criminoso e de seus destinadores-manipuladores, que pagaram para que cometesse o crime, de modo que o leitor acompanha a manipulação do criminoso desde o início da história. Na outra narrativa policial em análise, o conto "Os três ratos cegos”, o leitor só fica sabendo que o detetive já conhecia a identidade do criminoso depois que ele é capturado, ou seja, depois que o detetive Tanner prendeu Jim é que o leitor descobre que Tanner já sabia quem era o criminoso desde que chegou à pensão para realizar sua performance.

Outra característica das narrativas de criminoso, de sanção pragmática, que as diferem das narrativas de detetive, é que naquelas a punição recebida pelo criminoso sempre é descrita na história, ao passo que nos romances de sanção cognitiva o que interessa ao leitor é a descoberta da identidade do criminoso, não importando muito se depois disso ele será preso, enforcado, processado etc.

Neste trabalho, destacamos quatro narrativas policiais e, a partir delas, pudemos comprovar a idéia de que a "narrativa de detetive”, de sanção cognitiva, é mais misteriosa. Isso porque, entre os quatro romances selecionados, sabendo-se que dois apresentavam a sanção cognitiva e o os outros dois a sanção pragmática, observamos que a narrativa “Os três ratos cegos”, de sanção pragmática, carrega uma das características mais marcantes do romance de sanção cognitiva, qual seja, a de que a identidade do criminoso só é revelada no final da investigação. Isso porque o detetive do conto em questão, Tanner, não compartilhou com o leitor o saber sobre a identidade 
do criminoso, embora ele já o possuísse quando realizou sua performance, de modo que só é possível saber que se trata de uma narrativa de sanção pragmática ao final da leitura.

Dessa forma, nas narrativas de criminoso, em que aparece a sanção pragmática, grande parte do mistério acerca do desenlace da narrativa, isto é, a identidade do criminoso, já foi desvendado e entregue ao leitor, antes mesmo que ele formulasse suas hipóteses. Dessa forma, o único sentido para se continuar a leitura das narrativas desse tipo é observar como o detetive fará a perseguição, pois já é certo que ele conseguirá capturar o criminoso. Nas narrativas de detetive, por sua vez, o mistério se faz presente do início ao fim e de diferentes maneiras. A princípio, o leitor nem imagina que um crime será cometido; quando isso ocorre, ele insiste em trabalhar junto com o detetive para encontrar o culpado, acompanhando os passos da investigação. Quando essa é concluída pelo detetive, o leitor quer saber como ele será punido. Com isso, a narrativa torna-se misteriosa e enigmática do início ao fim.

Nos romances policiais o crime desestrutura a ordem estabelecida pela sociedade e o detetive é acionado para restabelecê-la. Da mesma maneira que o criminoso teve êxito em sua performance, imagina-se que o detetive também o terá. Em outras palavras, se o detetive foi acionado para restabelecer a ordem na narrativa, ele provavelmente conseguirá fazê-la. Assim, o leitor se prende à narrativa do início ao final, pois quer descobrir quem é o criminoso - o que não ocorre na sanção pragmática. A partir das diferenças entre os dois tipos de sanção aqui apresentadas, podemos concluir que as narrativas de detetive, nas quais aparece a sanção cognitiva, são mais coerentes com a proposta de mistério do romance policial porque o mantém na maior parte de sua extensão.

\section{Notas}

\footnotetext{
${ }^{1} \mathrm{O}$ assassinato é o crime praticado em quase todos os romances policiais por ser romanticamente superior aos outros crimes, como roubos, seqüestros etc.

${ }^{2}$ Martins (2000) distingue ainda um terceiro tipo, que engloba a sanção cognitiva e a sanção pragmática ao mesmo tempo. Esse terceiro tipo, porém, não foi considerado aqui, visto que nenhum dos romances estudados apresentou essa característica.
}

\section{REFERÊNCIAS BIBLIOGRÁFICAS}

CHRISTIE, Agatha. Assassinato no Expresso Oriente. Rio de Janeiro: Nova Fronteira, 1933.

. Um corpo na biblioteca. $4^{\text {a }}$ ed. Rio de Janeiro: Nova Fronteira, 1942.

"Os três ratos cegos". In: de Janeiro: Nova Fronteira, 1979.

BARROS, Diana Luz Pessoa de. Teoria do discurso. São Paulo: Atual, 1988.

Teoria semiótica do texto. São Paulo: Ática, 1990.

CORTINA, Arnaldo. Leitor contemporâneo. Os livros mais vendidos no Brasil de 1966 a 2004. Araraquara, 2006. Tese (Livre-docência). Faculdade de Ciências e Letras. Universidade Estadual Paulista. 
FORSYTH, Frederick. O dia do Chacal. São Paulo: Record, 1999. 19ª Ed.

GREIMAS, Algirdas Julien. Sobre o sentido. Ensaios semióticos. Tradução: Ana Cristina C. Cezar et al. Petrópolis: Vozes, 1975.

MARTINS, Marcelo Machado. Narrativa policial: uma abordagem semiótica. São Paulo, 2000. Dissertação (Mestrado) - Faculdade de Filosofia, Letras e Ciências Humanas, Universidade de São Paulo.

Como citar este artigo:

MASSI, Fernanda \& CORTINA, Arnaldo. A sanção cognitiva e a sanção pragmática nos romances policiais da década de 1970. Estudos Semióticos. [online] Disponível na Internet via WWW.URL: http://www.fflch.usp.br/dl/semiotica/es. Editor Peter Dietrich. Número 4, São Paulo, 2008. Acesso em "dia/mês/ano". 